\title{
Baroreflex sensitivity and responses to the Valsalva manoeuvre in subjects with diabetes mellitus
}

\author{
T. BENNETT, ${ }^{1}$ D. J. HOSKING, AND J. R. HAMPTON \\ From the Department of Physiology, Nottingham University Medical School, \\ and Department of Medicine, General Hospital, Nottingham
}

SYNOPSIS Baroreflex sensitivity was measured in a group of diabetic patients from the slope of the regression of pulse interval on systolic arterial pressure, during elevation of pressure induced by $\vec{\circ}$ phenylephrine. The response to Valsalva's manoeuvre was assessed in the same subjects. There was a good correlation between the two tests in the identification of patients with a parasympathetic autonomic disturbance, but measurements of baroreflex sensitivity were more readily quantifiable than were the responses to Valsalva's manoeuvre. Furthermore, baroreflex sensitivity could be measured in patients with sympathetic nervous dysfunction in whom vagal function could not be $\omega$ assessed by means of the Valsalva manoeuvre. Measurement of baroreflex sensitivity is likely to be suitable for longitudinal studies of the progress of diabetic autonomic neuropathy.

Recent investigations have shown that it is possible to assess, quantitatively, the sensitivity of the baroreflex in man (Smyth et al., 1969; Bristow et al., 1971, 1974; Gribbin et al., 1971; Pickering et al., 1972). The method requires the intravenous injection of a substance, such as phenylephrine, that has a direct vasoconstrictor action on peripheral blood vessels. This results in an elevation of systolic arterial blood pressure which gives rise to a reflex bradycardia. The rise in pressure and the lengthening of the pulse interval are linearly related, and the slope of the relation may be taken as an index of the sensitivity of the baroreflex.

The sensitivity of this reflex has been shown to be reduced in hypertension (Gribbin et al., 1971) and in heart disease (Eckberg et al., 1971). This test was used in the present investigation of a group of diabetic subjects, some of whom had signs of autonomic neuropathy. It was intended to determine whether autonomic dysfunction of this aetiology was readily assessed by the method described above and, furthermore, whether the precision of the method was such as to allow the

\footnotetext{
1 Correspondence to: Dr T. Bennett, Department of Physiology, Medical School, University of Nottingham, University Park, Nottingham, NG7 2RD.

(Accepted 10 October 1975.)
}

severity of the dysfunction to be assessed, as basis for following the natural history of th disease.

The present investigation also included a examination of the cardiovascular responses the Valsalva manoeuvre (see Johnson and के Spalding, 1974). This test has the advantage that it allows the study of the reflex effects of both a fall and an elevation of blood pressure. The subject raises his intrathoracic pressure by attempting to expire against a closed airway and thereby impedes venous return to the heart. As a result, systolic, diastolic, and pulse pressures fall initially, but subsequently systolic and diastolic pressures tend to rise again, because of tachycardia and peripheral vasoconstriction. When the intrathoracic pressure is released, venous return, and hence cardiac output, are increased. The increased cardiac output is forced into a constricted peripheral vasculature, and results in a marked overshoot of systolic and diastolic pressures, the heart rate slows, returning pressures towards normal levels. The increase in heart rate during the manoeuvre is a reflex resulting largely from the exposure of baro- o receptors to lowered pressures; the decrease in $N$ heart rate after the manoeuvre is a reflex due to the exposure of baroreceptors to increased 
pressures. The bradycardia is due to vagal activity (Elisberg et al., 1953; Johnson and Spalding, 1974), but the cause of the tachycardia is controversial (Elisberg et al., 1953; Leon et al., 1970; Johnson and Spalding, 1974). Because of the many interacting factors involved, grading of the responses to this manoeuvre is always likely to be difficult. The results from this test have been included for comparison with the findings relating to baroreflex sensitivities.

\section{METHODS}

Seventeen diabetic subjects (nine males, eight females) were investigated at the request of their physicians; the subjects gave their fully informed consent to the study. They ranged in age from 21 to 71 years (mean 46.4) and the time since diagnosis of the disease ranged from one to 45 years. All except two patients had one or more of the following features: impotence (eight patients), postural hypotension (six subjects), disordered sweating (five subjects), diarrhoea (seven subjects), peripheral neuropathy (12 subjects), peripheral vascular disease (three subjects), and retinopathy (nine subjects). Five, normal, nondiabetic subjects were also examined. Their ages were between 21 and 56 years (mean 40.5); these subjects were all males who had no clinical disorders.

The subject lay supine on a bed; arterial pressure was recorded from a needle ( 23 gauge) inserted, percutaneously, into the right femoral artery. The needle was connected to a saline-filled Teflon tube attached to a pressure transducer (Bell and Howell); the output from the transducer was fed into a photographic (Cambridge Scientific Instruments) or an ultra-violet recorder (S.E. Laboratories).

RESPONSE TO INTRAVENOUS PHENYLEPHRINE When arterial pressure and heart rate had stabilized, phenylephrine (dissolved in saline) was injected into an antecubital vein; the initial dose was $50 \mu \mathrm{g}$, and the dose was increased to a maximum of $300 \mu \mathrm{g}$, or until a rise of at least $4 \mathrm{kPa}(30 \mathrm{~mm} \mathrm{Hg})$ in systolic blood pressure was obtained. From the continuous record of arterial pressure, the systolic pressures and the pulse intervals were measured. The reflex sensitivity was taken as the slope of the line (obtained by linear regression analysis) relating the pulse interval of each beat to the systolic pressure of the preceding beat, from the point at which systolic pressure started to rise until it reached a peak (Smyth et al., 1969; Bristow et al., 1971). Usually three separate estimates of the baroreflex slope were available, but the data were pooled and the sensitivities given in the results are derived from all the separate values of pulse interval and systolic arterial blood pressure for each subject. In all cases except subject 19, the linear regression of pulse interval on systolic arterial blood pressure was significant $(P<0.05)$.

VALSALVA'S MANOEUVRE The subject was initially instructed in the procedure and practised several times without measurements being taken. After a continuous recording of resting arterial pressure had been made, the subject was asked to blow a column of mercury up to a height of $40 \mathrm{~mm}$ for $10 \mathrm{~s}$; this procedure has been shown to evoke the most reliable responses (Levin, 1966). Arterial pressure was recorded continuously throughout and after the manoeuvre, until it had returned to resting levels; each subject performed the manoeuvre at least twice; the results given in the text are mean values.

It has recently been suggested that abnormality of Valsalva responses should be decided on the basis of: (1) absence of an arterial pressure overshoot after the manoeuvre; (2) the occurrence of a lower heart rate during the manoeuvre than after it; and (3) a fall in mean blood pressure, during the manoeuvre, below $50 \%$ of the resting mean blood pressure (Johnson and Spalding, 1974).

From the arterial pressure recording the following were measured: (a) resting systolic and diastolic arterial pressures, (b) resting heart rate (assessed from the intervals between systolic pressure peaks, over a period of $10 \mathrm{~s}$ ), (c) systolic and diastolic arterial pressures at the end of the $10 \mathrm{~s}$ manoeuvre, (d) heart rate at the end of the manoeuvre (taken from the interval between the last two systolic pressure peaks), (e) maximum systolic and diastolic arterial pressures after the manoeuvre, and (f) minimum heart rate after maximum arterial pressures were achieved (assessed from the longest interval between systolic arterial pressure peaks).

Results were analysed by Student's unpaired $t$ test ; values given in the text are mean \pm SEM. In conformity with the usage of SI units, arterial pressures are given in $\mathrm{kPa}$ (where $1 \mathrm{~mm} \mathrm{Hg} \bumpeq 0.133 \mathrm{kPa}$ ); heart rates are given in beats. $\mathrm{s}^{-1}$.

\section{RESULTS}

NORMAL SUBJECTS The five (1-5) normal subjects had baroreflex sensitivities ranging from 46.6 to $103.8 \mathrm{~ms}$. $\mathrm{kPa}^{-1}$ (mean $=67.7 \pm 11.3$; Fig. 1A). These subjects showed the normal pattern of changes in response to the Valsalva manoeuvre (see introduction, Table, Fig. 2).

DIABETIC SUBJECTS Seven diabetic subjects 
TABLE

VALSALVA RESPONSE

\begin{tabular}{|c|c|c|c|c|c|c|c|c|c|}
\hline \multirow[t]{2}{*}{ Subject } & & \multirow{2}{*}{$\begin{array}{c}\text { Baroflex } \\
\text { sensitivity } \\
\left(m s . \mathrm{kPa}^{-1}\right)\end{array}$} & \multicolumn{2}{|c|}{ Before } & \multicolumn{2}{|c|}{ End } & \multicolumn{2}{|c|}{ After } & \\
\hline & & & $H R$ & $B P$ & $H R$ & $B P$ & $H R$ & $B P$ & \\
\hline \multirow{22}{*}{ Diabetic \{} & 1 & 52.6 & 1.4 & $19.1 / 10.1$ & 2.0 & $18.1 / 14.4$ & 1.0 & $31.4 / 13.3$ & \multirow{12}{*}{$\begin{array}{l}\text { Normal } \\
\text { response }\end{array}$} \\
\hline & 2 & 51.1 & 1.3 & $11.7 / 7.7$ & 1.7 & $8.6 / 8.1$ & 1.0 & $16.2 / 10.4$ & \\
\hline & 3 & 85.0 & 1.5 & $12.9 / 9.0$ & 1.8 & $12.0 / 10.9$ & 1.0 & $17.0 / 12.0$ & \\
\hline & 4 & 103.8 & 1.3 & $16.9 / 8.8$ & 2.1 & $14.0 / 8.1$ & 1.0 & $21.4 / 10.8$ & \\
\hline & 5 & 46.6 & 1.2 & $17.3 / 8.0$ & 1.6 & $16.6 / 10.6$ & 0.8 & $21.3 / 10.6$ & \\
\hline & 6 & 103.0 & 1.3 & $16.0 / 8.0$ & 1.7 & $20.0 / 15.3$ & 1.2 & $20.2 / 10.6$ & \\
\hline & 7 & 109.8 & 1.6 & $22.3 / 14.1$ & 2.3 & $27.7 / 22.9$ & 1.4 & $24.5 / 15.4$ & \\
\hline & 8 & 63.9 & 2.0 & $18.1 / 10.1$ & 2.6 & $18.1 / 16.5$ & 1.0 & $30.9 / 13.3$ & \\
\hline & 9 & 53.4 & 1.8 & $17.3 / 7.5$ & 2.3 & $9.3 / 7.4$ & 0.7 & $19.4 / 8.5$ & \\
\hline & 10 & 50.4 & 1.8 & $22.3 / 12.2$ & 2.3 & $23.9 / 17.0$ & 0.7 & $30.3 / 15.4$ & \\
\hline & 11 & 78.2 & 1.3 & $18.6 / 8.0$ & 2.0 & $18.4 / 14.1$ & 1.1 & $24.7 / 11.2$ & \\
\hline & 12 & 68.4 & 1.2 & $16.8 / 8.5$ & 2.0 & $19.4 / 15.4$ & 1.0 & $21.8 / 10.0$ & \\
\hline & 13 & 27.1 & 1.3 & $17.6 / 9.0$ & 1.8 & $13.3 / 11.2$ & 1.1 & $26.1 / 11.2$ & Reduced \\
\hline & 14 & 25.6 & 1.5 & $26.6 / 11.7$ & 2.0 & $24.5 / 21.8$ & 1.4 & $38.8 / 17.0$ & bradycardia \\
\hline & 15 & 12.8 & 1.4 & $19.7 / 5.9$ & 1.6 & $16.5 / 11.2$ & 1.4 & $21.5 / 5.9$ & No \\
\hline & 16 & 22.6 & 1.5 & $12.5 / 8.0$ & 1.9 & $12.2 / 11.2$ & 1.5 & $17.3 / 10.6$ & No \\
\hline & 17 & 12.8 & 1.5 & $18.6 / 8.2$ & 1.8 & $14.9 / 14.1$ & 1.5 & $21.5 / 10.9$ & bradycardia \\
\hline & 18 & 33.1 & 1.4 & $26.1 / 10.9$ & 1.9 & $20.7 / 14.1$ & 1.4 & $26.6 / 12.0$ & \\
\hline & 19 & 0.8 & 1.5 & $28.2 / 12.2$ & 1.9 & $15.4 / 14.6$ & 1.5 & $28.2 / 12.6$ & Little or no \\
\hline & 20 & 4.5 & 1.7 & $23.7 / 10.6$ & 1.9 & $21.3 / 14.9$ & 1.7 & $24.5 / 11.7$ & pressure \\
\hline & 21 & 19.5 & 1.5 & $20.0 / 14.6$ & 1.9 & $18.6 / 14.4$ & 1.5 & $18.1 / 15.4$ & overshoot \\
\hline & 22 & 23.3 & 1.5 & $20.2 / 11.7$ & 1.9 & $17.6 / 12.8$ & 1.7 & $19.2 / 10.6$ & \\
\hline
\end{tabular}

$\mathrm{HR}=$ heart rate $(\mathrm{Hz}) ; \mathrm{BP}=$ femoral arterial pressure $(\mathrm{kPa}) .(1 \mathrm{kPa}=7.5006 \mathrm{~mm} \mathrm{Hg})$.

Measurements for the Valsalva response were made at the end of the $10 \mathrm{~s}$ manoeuvre, and at the peak of the arterial pressure overshoot, when it was present. Baroreflex sensitivity was measured as described in Methods.

(6-12) had baroreflex sensitivities that were not significantly different from those of the nondiabetic subjects $\left(\right.$ mean $=75.2 \pm 9.0 \mathrm{~ms} . \mathrm{kPa}^{-1}$; Fig. 1B) and, like the latter, their responses to Valsalva's manoeuvre were normal (Table; Fig. 2).

Two diabetic subjects $(13,14)$ had low baroreflex sensitivities $\left(27.1\right.$ and $25.6 \mathrm{~ms}$. $\mathrm{kPa}^{-1}$ respectively), although their responses to the Valsalva manoeuvre appeared to be normal (Table). However, examination of the relation between the systolic pressure overshoot and the bradycardia after the Valsalva manoeuvre indicated that their vagal responsiveness was less than that of the subjects above (Table).

The remaining eight subjects all had very low baroreflex sensitivities, but they could be divided into two groups on the basis of their responses to Valsalva's manoeuvre. The mean baroreflex sensitivity of three subjects (15-17) was $15.8 \pm$ $3.0 \mathrm{~ms} . \mathrm{kPa}^{-1}$; these subjects showed no slowing of the heart when arterial pressure was raised after Valsalva's manoeuvre (Table). The other subjects (18-22) showed little or no overshoot of arterial pressure after Valsalva's manoeuvre, and no bradycardia (Table). One of these subjects (18 had a baroreflex sensitivity of $33.1 \mathrm{~ms}$. $\mathrm{kPa}-\overrightarrow{0}$ but the other subjects in this group had even oे lower baroreflex sensitivities when tested with phenylephrine $\left(\right.$ mean $\left.=12.0 \pm 5.6 \mathrm{~ms} . \mathrm{kPa}^{-1}\right)$. The relationships between $\mathrm{R}-\mathrm{R}$ intervals in the electrocardiograph and systolic blood pressures for the diabetic subjects 13-22 are shown in Fig. 1C.

There was a significant difference $(\mathrm{P}<0.001)$ between the mean baroreflex sensitivity of the subjects who responded normally to the Valsalva manoeuvre (subjects 6-12; baroreflex sensitivity $=75.2 \pm 9.0 \mathrm{~ms}$. $\mathrm{kPa}^{-1}$ ) and those who showed some clear-cut abnormality (subjects $15-22$; baroreflex sensitivity $=15.8 \pm 3.8 \mathrm{~ms}$. $\left.\mathrm{kPa}^{-1}\right)$. There were no significant differences in the ages, resting heart rates, or resting arterial pressures of the subjects in these two groups. The relationship between baroreflex sensitivity and response to the Valsalva manoeuvre is illustrated in Fig. 2.

All subjects showed a tachycardia during the Valsalva manoeuvre (Table). There was no significant difference between the tachycardia 

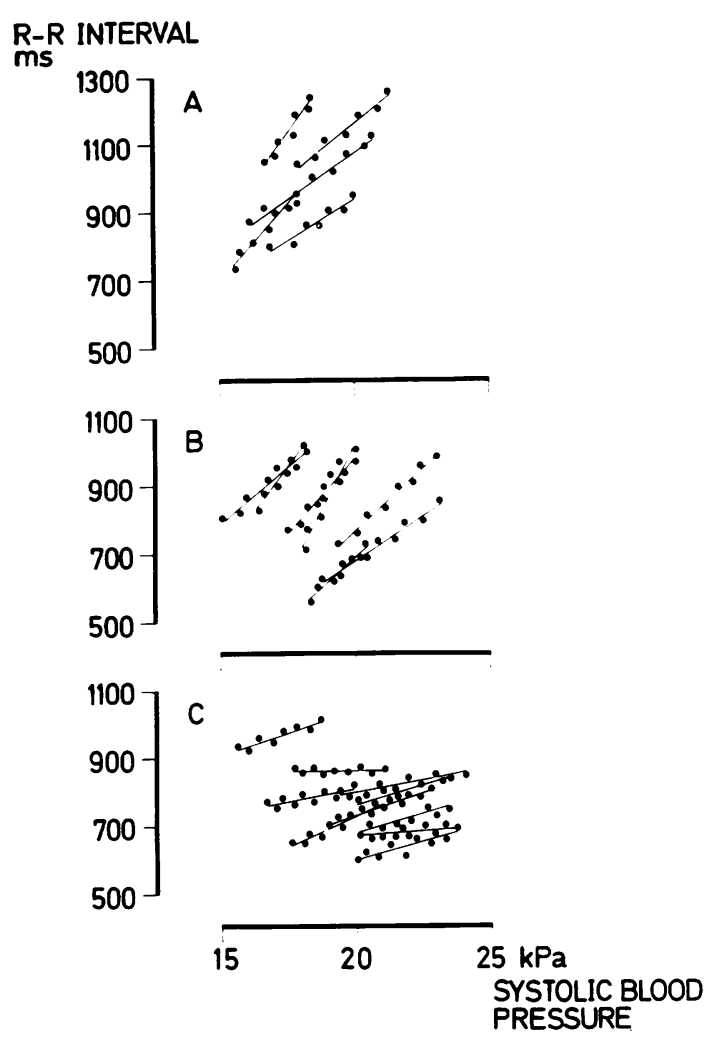

FIG. 1. Linear regressions of $R-R$ interval on systolic arterial blood pressure during elevation of the latter by intravenous infusion of phenylephrine (see Methods). The points indicate values for $R-R$ interval and systolic arterial blood pressure, and the lines are the mean regressions for individual subjects. The slopes of the regression lines are taken as the baroreflex sensitivities and are given in the Table. A. Regressions for five control subjects (1-5). B. Regressions for seven normal diabetic subjects (6-12). C. Regressions for 10 abnormal subjects (13-22). Note the similarity of slopes in $\mathrm{A}$ and $\mathrm{B}$ and the depressed slopes in $\mathrm{C}$.

seen in the control group (subjects 1-5; increase $=0.50 \pm 0.08$ beats. $\mathrm{s}^{-1}$ ) and the tachycardia seen in the diabetic subjects who showed a normal Valsalva response (subjects 6-12; increase $=0.60 \pm 0.05$ beats. $\mathrm{s}^{-1}$ ). However, there was a significant difference $(P<0.005)$ between the tachycardia seen in this latter group and that seen in the group of diabetic subjects who showed an abnormal Valsalva response (subjects 15-22; increase $=0.35 \pm 0.03$ beats.$\left.s^{-1}\right)$.

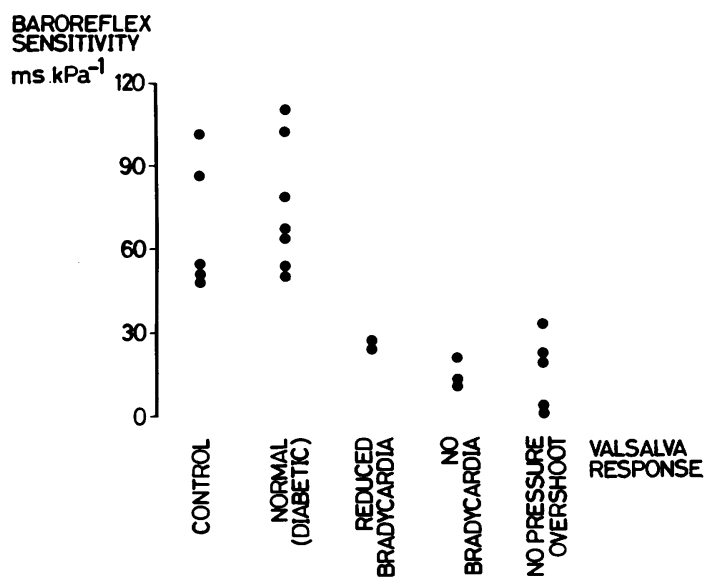

FIG. 2. The relationship between the baroreflex sensitivity and the response to the Valsalva manoeuvre in five non-diabetic and 17 diabetic subjects.

\section{DISCUSSION}

It has been claimed that the changes in heart rate evoked by a rise or a fall in arterial blood pressure are mediated through the vagus nerves (for example, Leon et al., 1970; Pickering et al., 1972). Some workers have, however, found the cardiac sympathetic nerves to be involved in the tachycardia evoked by hypotension (Robinson et al., 1966; Fitzgerald, 1970), while others have claimed that the sympathetic and parasympathetic systems may both be involved (Ekue et al., 1974).

The cardiovascular responses to Valsalva's manoeuvre are complex. It is clear that the bradycardia, elicited by the overshoot in arterial pressure, is vagally mediated (for example, Elisberg et al., 1953; Johnson and Spalding, 1974); it has been suggested that the tachycardia seen during the manoeuvre is due to removal of vagal tone (Leon et al., 1970; see Johnson and Spalding, 1974). Other evidence suggests that the tachycardia is due to sympathetic mechanisms (Elisberg et al., 1953; Boakes et al., 1973). In the present study, seven subjects (15-22) were found to have lost all signs of reflex vagal activity, yet they showed a marked tachycardia during Valsalva's manoeuvre. Thus, from the present results, it seems that this tachycardia may be due to sympathetic mechanisms, but this does not 
exclude the possibility of some vagal involvement in normal subjects. Indeed, there is some support for this suggestion, since the subjects who were devoid of cardiac vagal reflexes showed a smaller increase in heart rate during Valsalva's manoeuvre than did those who retained their vagal function.

Sharpey-Schafer and Taylor (1960) claimed that an afferent lesion was responsible for the abnormal baroreflexes in diabetic subjects, but other studies suggest that the lesion is associated with the efferent postganglionic vasoconstrictor fibres, since blood vessels in diabetic subjects have been shown to exhibit a classical denervation supersensitivity to catecholamines (Bárány, 1955; Moorhouse et al., 1966; Frank et al., 1972). From the present work, it seems most likely that the lesion is efferent, since in eight subjects (15-22) the cardiac responses to hypotension were preserved while those to hypertension were lost; it would be difficult to explain these observations by invoking an afferent lesion.

The present findings can be related to observations on orthostatic reflexes in the same subjects, reported elsewhere (Bennett et al., 1975a). Subjects $6-12,13-15$, and 18 of the present study showed little change in systolic arterial blood pressure and a normal, moderate tachycardia on standing. As pointed out previously, impairment of vagal function (as seen in subjects 13-15) does not appear to interfere with orthostatic adaptation. In subject 18 there was no overshoot of arterial pressure after the Valsalva manoeuvre, but cardiovascular responses to standing appeared normal; such dissociation has been reported previously (see Johnson and Spalding, 1974). The remaining subjects $(16,17$, 19-22) all showed a fall in systolic arterial blood pressure on standing. However, in subjects 16 and 17 there was a recovery of systolic arterial blood pressure without a persistent increase in heart rate (Fig. 3b in Bennett et al., 1975a); these two subjects showed an overshoot in arterial pressure after the Valsalva manoeuvre. Such observations taken together indicate that vasoconstrictor activity was preserved, but perhaps impaired (Johnson and Spalding, 1974). Subjects 19-22 showed an abnormal fall in systolic arterial blood pressure and a persistent and abnormal increase in heart rate on standing.
As reported here, these subjects showed no overshoot in arterial blood pressure after Valsalva's manoeuvre. These findings are consistent with a loss of vasomotor function due to an efferent lesion, since the afferent input responsible for eliciting a reflex tachycardia was obviously functional.

It is apparent that, for the Valsalva manoeuvre, assessment of responses in terms of heart rate alone (Levin, 1966; Nathanielsz and Ross, 1967; Ewing et al., 1973) cannot provide adequate information about patterns of autonomic failure, since loss of bradycardia after the manoeuvre may be due to absence of an arterial pressure overshoot or to vagal dysfunction. Furthermore, consideration of the ratio between the heart rate during the manoeuvre to the heart rate after the manoeuvre (Levin, 1966; Ewing et al., 1973) fails to recognize the different mechanisms involved in the tachycardia and the bradycardia. Thus, in the present study, four subjects $(16,180$ 19 , and 21) had heart rate ratios in the normap $\infty$ range used by Ewing et al. (1973), and yet the showed no bradycardia after the manoeuvre $\frac{\alpha}{2}-$ relative to the resting heart rate.

As alluded to above, in the absence of ar arterial pressure overshoot after the Valsalva manoeuvre, the test cannot be used to assess vagal function. This difficulty is avoided by using the technique for measuring baroreflex sensitivity devised by Smyth et al. (1969). In the present work, five subjects (18-22) were encountered who showed little or no arterial pressure overshoot after the Valsalva manoeuvre-an indication of defective vasoconstrictor function (see Johnson and Spalding, 1974). Interestingly, these subjects all had very low baroreflex sensitivities; thus it appears that they had both vasoconstrictor and vagal defects. Certain other subjects had signs of vagal defects only (subjects 15-17); however, no subjects appeared to have normal vagal function associated with defective vasoconstrictor mechanisms, as assessed by the present tests. While this appears to be generally true (Bennett et al., 1975a), the observations made depend, to an extent, on the tests used (Bennett et al., 1975b).

It appears that baroreflex sensitivity is readily quantitated using the method devised by Smyth et al. (1969). The present findings indicate a more 
clear-cut differentiation of subjects into normal and abnormal types using this method than is possible by examination of their responses to the Valsalva manoeuvre. An added advantage of the technique is that it provides a numerical estimate of baroreflex sensitivity; this raises the possibility that longitudinal studies may be carried out and thus the natural history of diabetic neuropathy may be followed using this and other methods (Bennett et al., 1975a, b).

We are grateful to Professor A. D. M. Greenfield and Dr P. H. Fentem for their constructive criticisms of the manuscript, and to Mrs P. Riggott for technical assistance. This work was supported by a grant from the Nuffield Foundation.

\section{REFERENCES}

Bárány, F. R. (1955). Abnormal vascular reactions in diabetes mellitus. Acta Medica Scandinavica, 152, suppl. 304, 1-129.

Bennett, T., Hosking, D. J., and Hampton, J. R. (1975a). Cardiovascular control in subjects with diabetes mellitus. British Medical Journal, 2, 585-587.

Bennett, T., Hosking, D. J., and Hampton, J. R. (1975b). Cardiovascular reflex responses to apnoeic face immersion and to mental stress in subjects with diabetes mellitus. Cardiovascular Research. (In press.)

Boakes, A. J., Boeree, B. H., and Prichard, B. N. C. (1973). Dose response studies to oxprenalol, pindolol, practolol and sotalol on tilt, Valsalva and exercise tachycardia. Naunyn-Schmiedeberg's Archives of Pharmacology, 279, suppl. (abstract 67).

Bristow, J. D., Brown, E. B., Cunningham, D. J. C., Howson, M. G., Lee, M. J. R., Pickering, T. G., and Sleight, P. (1974). The effects of raising alveolar $\mathrm{P}_{\mathrm{CO}_{2}}$ and ventilation separately and together on the sensitivity and setting of the baroreceptor cardiodepressor reflex in man. Journal of Physiology, 243, 401-426.

Bristow, J. D., Brown, E. B., Cunningham, D. J. C., Howson, M. G., Petersen, E. S., Pickering, T. G., and Sleight, P. (1971). Effect of bicycling on the baroreflex regulation of pulse interval. Circulation Research, 28, 582-592.
Eckberg, D. L., Drabinsky, M., and Braunwald, E. (1971). Defective cardiac parasympathetic control in patients with heart disease. New England Journal of Medicine, 285, 877-883.

Ekue, J. M. K., Shanks, R. G., and Walsh, M. J. (1974). Observations on the effect of $\beta$-adrenoreceptor blocking drugs on glyceryl trinitrate tachycardia. British Journal of Clinical Pharmacology, 1, 19-26.

Elisberg, E. I., Miller, G., Weinberg, S. L., and Katz, L. N. (1953). The effect of the Valsalva manoeuvre on the circulation. 2. American Heart Journal, 45, 227-236.

Ewing, D. J., Campbell, I. W., Burt, A. A., and Clarke, B. F. (1973). Vascular reflexes in diabetic autonomic neuropathy. Lancet, 2, 1354-1356.

Fitzgerald, J. D. (1970). A new test of the degree of adrenergic beta receptor blockade. International Journal of Clinical Pharmacology, 4, 125-130.

Frank, H. J., Frewin, D. B., Robinson, S. M., and Wise, P. H. (1972). Cardiovascular responses in diabetic dysautonomia. Australian and New Zealand Journal of Medicine, 1, $1-7$.

Gribbin, B., Pickering, T. G., Sleight, P., and Peto, R. (1971). Effect of age and high blood pressure on baroreflex sensitivity in man. Circulation Research, 29, 424-431.

Johnson, R. H., and Spalding, J. M. K. (1974). Disorders of the Autonomic Nervous System. Blackwell: Oxford.

Leon, D. F., Shaver, J. A., and Leonard, J. J. (1970). Reflex heart rate control in man. American Heart Journal, 80, 729-739.

Levin, A. B. (1966). A simple test of cardiac function based upon the heart rate changes induced by the Valsalva manoeuvre. American Journal of Cardiology, 18, 90-99.

Moorhouse, J. A., Carter, S. A., and Doupe, J. (1966). Vascular responses in diabetic peripheral neuropathy. British Medical Journal, 1, 883-888.

Nathanielsz, P. W., and Ross, E. J. (1967). Abnormal response to Valsalva maneuver in diabetics. Diabetes, 16, 462-465.

Pickering, T. G., Gribbin, B., and Sleight, P. (1972). Comparison of the reflex heart rate response to rising and falling arterial pressure in man. Cardiovascular Research, 6 , 277-283.

Robinson, B. F., Epstein, S. E., Beiser, G. D., and Braunwald, E. (1966). Control of heart rate by the autonomic nervous system. Circulation Research, 19, 400-411.

Sharpey-Schafer, E. P., and Taylor, P. J. (1960). Absent circulatory reflexes in diabetic neuritis. Lancet, 1, 559-562.

Smyth, H. S., Sleight, P., and Pickering, G. W. (1969). Reflex regulation of arterial pressure during sleep in man. Circulation Research, 24, 109-121. 